ISSN 1112-9867

Available online at

http://www.jfas.info

\title{
NEW APPROACH TO PREDICT PRESSURE PRODUCED BY ELASTIC TEXTILE IN THE THEREPEUTIC TREATMENT OF VENOUS LEG
}

\author{
R. Halfaoui ${ }^{1, *}$ and B. Chemani ${ }^{2}$ \\ ${ }^{1,2}$ Faculty of Engineering Sciences, Laboratory of Processing and Shaping of Fibrous \\ Materials and Polymers, M'Hamed Bougarra University, Boumerdes, 35000, Algeria
}

Received: 17 December 2015 / Accepted: 08 April 2016 / Published online: 01 May 2016

\begin{abstract}
This paper presents the first theoretical and practical work on compression therapy using the Laplace law to estimate pressures under the bandages. Three woven articles are considered: the first uses a highly-twisted cotton warp yarn, the second a polyamide warp yarn and the third a spandex yarn warped with a cotton yarn. Starting from these woven fabrics, three models, $\mathrm{E}_{5}, \mathrm{E}_{6}$ and $\mathrm{Ef}$ have been developed with respective elongations of $108 \%, 86 \%$ and $92 \%$ and specific mechanical behavior. The results show that than the single layer bandages develop much higher pressure than the multilayer bandages but the multilayer bandages exert much more uniform pressure than single layered bandages. Obtaining uniform pressure along the length of the leg is a positive result in this treatment. Average circumferences of the human body are used for the pressure calculations in four zones: $\mathrm{C}_{1}, \mathrm{C}_{2}, \mathrm{C}_{3}$ and $\mathrm{C}_{4}$.
\end{abstract}

Keywords: elastic textile; weaving technology; venous leg; pressure.

Author Correspondence, e-mail: halfaoui@univ-boumerdes.dz

doi: http://dx.doi.org/10.4314/jfas. v8i2.9 


\section{INTRODUCTION}

Due to the lower blood pressure in the venous system compared to the arterial system, the walls of the veins are thinner than the companion arteries and they have larger diameters. Thin walls enable veins to have a large capacity for expansion. This and the large diameter explain why veins store about $60 \%$ to $75 \%$ of the blood [1]. The valves are cusps and attached by their convex edges to the venous wall. Their concave margins are directed with the flow and lie against the wall as long as the flow is towards the heart. When blood flow reverses, the valves close [2]. The venous network in the lower limb is divided into three systems that work together to return blood to the heart. These systems are: the superficial veins, the deep veins and the perforator veins [3]. There are three major deep veins below the knee: the anterior tibia vein, posterior tibia vein and peroneal vein.

Above the knee, there are two major branches: the popliteal vein, which is formed by the tibia and peroneal veins, and the femoral vein which is the continuation of the popliteal vein [4]. Venous sinuses are closely related to deep veins as they are embedded in the belly of the calf muscles and are able to dilate and hold a large amount of blood. These veins play a significant role in the calf muscle pump function. Blood flow resistance is the opposition to flow and is a measure of the amount of friction blood encounters as it passes through the vessel. Blood viscosity, blood vessel length and diameter are factors influencing blood flow resistance. The primary function of the venous circulation is to return blood to the heart. There are four different mechanisms which work together and assisted by venous valves to help venous return [5].

As people inhale, abdominal pressure increases, squeezing the veins in the ventral body cavity and forcing blood towards the heart. At the same time, pressure in the chest decreases, allowing thoracic veins to expand and speeding blood entry into the right atrium. As a result of arteries expansion due to heart contraction, veins that accompany deep arteries get stretched and attened, which aid in driving venous blood towards the heart. Weight bearing is thought to empty blood from the foot when the foot gets at during a gait cycle. During normal locomotion, the three venous pumps; the foot pump, the distal and proximal calf pumps work together to pump blood back to the heart. 
Before weight bearing, the ankle is dorsiflexed, emptying the distal calf pump. Weight bearing empties the foot using foot pump. Immediately after the weight bearing, the ankle is plantarexed and the proximal calf pump empties blood into the popliteal vein and femoral vein [6]. A variety of bandages are used beneath compression bandages as padding layers in order to evenly distribute pressure and give protection [7]. These include polyurethane foam bandages and nonwoven orthopedic waddings but there is little published material which defines their use for this particular problem or whether they have the performance criteria necessary to provide adequate pressure distribution [8]. In order to distribute compression bandage pressure evenly around the limb it is essential that high pressures created at the tibia and fibula regions are absorbed by the padding bandage material. In bandages using single layer, the textile pressure is directly transmitted to the leg surface.

Compression therapy in the form of bandaging is an ancient treatment that has been used since to treat venous leg ulcers. The term compression could be defined as squeezing part of the body by mechanical influence. The logic behind using compression therapy in the treatment of venous leg is to provide an external pressure that works gainst the hydrostatic pressure and aids venous blood return.

In a recent systematic review of the literature about venous ulcers, compression increases the healing rates for venous leg compared with no compression and that high compression is more effective than moderate compression [9]. In another systematic review of the clinical evidence about the usage of compression to prevent the recurrence of venous ulcers, recurrence of ulcers may be less with the usage of high compression compared to low compression [10]. However, there is no evidence that high compression is more effective than moderate pressure for prevention (but there is limited research available) [11]. Therefore the aim of this study is to verify the pressure variation applied on the four leg zones.

\section{MATERIAL AND METHODS}

Using the Laplace law to estimate the pressure under bandage, it's necessary to take into account two factors: the bandage width B and the number of applied layers N. The calculated value of sub-bandage pressure is the average pressure to be exerted by bandage on leg whose 
circumference is known. To reduce the pressure variations in a given area under the bandage, padding can be used under compression materials [12]. Many types of textiles are composed of woven yarn, each thread composed of a plurality of fibers or yarns twisted together. Other, more advanced, the yarn cross sections may be elliptical, lenticular or racetrack. The factor that changes the most is the vessel diameter. The relation between the flow $(\mathrm{Q})$, the difference in blood pressure $\left(\Delta_{P B}\right)$ and the peripheral resistance $\left(\Delta_{R P}\right)$ is summarized in Equation 1.

$$
\mathrm{Q}=\frac{\Delta_{\mathrm{PB}}}{\Delta_{\mathrm{RP}}}
$$

The equation illustrates the importance of the difference in the blood pressure to the flow. However, in order to maintain a reasonable degree of simplicity, the banding pressure can be formulated by mathematical expression:

$$
\begin{aligned}
& P_{i}-P_{e}=\frac{T_{1}}{r}+\frac{T_{2}}{r} \\
& P=P_{i}-P_{e}=\frac{2 T}{r}
\end{aligned}
$$

$\left(\mathrm{P}_{\mathrm{i}}\right.$ - The internal pressure, $\mathrm{P}_{\mathrm{e}}$-The external pressure, $\mathrm{T}_{1}$ - The positive tension of textile, $\mathrm{T}_{2}$ The negative tension of textile, $\mathrm{R}$ - The curvature radius, $\mathrm{T}-$ Tension of bandage).

Equation (3) shows that pressure inside of a spherical surface is always greater than external pressure, but the difference tends to zero when the radius tends to infinity (when the surface becomes flat). However, pressure difference increases if the radius becomes smaller and tends to infinity as $\mathrm{r}$ tends to zero. When the wall is perfectly cylindrical, simply use the following (4).

$$
\mathrm{P}=\frac{\mathrm{T}}{\mathrm{r}}
$$

This law is applied in many sectors of science, including medicine, to calculate the forces exerted on blood vessels and alveoli filled with fluid. It is necessary to use the measuring unit's conversion of measurement, that is to say, using units pertaining to each other. The most common unit used is Pascal for measuring the pressure and Newton unit as measure of force, 
but in medical field, other units are often used. To reduce errors due to measurement units, it is important to consider a constant coefficient of conversion of measurement units $\mathrm{K}$ and equation (4) takes the following form:

$$
\begin{gathered}
P=\frac{T}{r} \cdot K \\
P=\frac{F}{2 \cdot \pi \cdot r \cdot B}
\end{gathered}
$$

F- the resultant force of the applied tension.

In case of a single bandage layer applied, the pressure is exerted on surface covered by the textile. This pressure will be determined by total force applied on fabric and width of the bandage in relation to the definition of pressure. Pressure applied is proportional to the force on the textile and inversely proportional to the application surface. The original formula for calculating pressure is expressed as:

$$
\mathrm{P}=\frac{\mathrm{T} \cdot \mathrm{N}}{\mathrm{L} \cdot \mathrm{B}}
$$

To move from one measurement unit to another and to avoid significant errors due to conversion of measurement units, it is useful to consider a constant $\mathrm{K}$ in final equation.

Consider the following case with: $\mathrm{N}=1$ layer $; \mathrm{B}=0,10 \mathrm{~m} ; \mathrm{r}=0,04 \mathrm{~m} ; \mathrm{T}=15 \mathrm{~N}=1.53 \mathrm{kgf}$; $\mathrm{L}=0.25 \mathrm{~m}$, the pressure $(\mathrm{P})$ under the bandage can be calculated as follows:

$$
\begin{gathered}
\mathrm{P}=\frac{15}{0.04 \cdot 0.1}=3750 \quad \mathrm{~Pa} \\
\mathrm{P}=3750 \cdot 0,0075=28.125 \mathrm{~mm} \mathrm{Hg}
\end{gathered}
$$

P' (mm Hg); T' (Kgf); L' (m); B' (m), then:

$$
\mathrm{P}^{\prime}=\frac{\mathrm{T}^{\prime} \cdot \mathrm{N} \cdot \mathrm{K}}{\mathrm{L}^{\prime} \cdot \mathrm{B}^{\prime}}
$$

After substitution numerical values given above:

$$
28.125=\frac{1.53 \cdot \mathrm{N} \cdot \mathrm{K}}{(2 \cdot 3,1416 \cdot 0.04 \cdot 100) \cdot 10}=\frac{1.53 \cdot \mathrm{K}}{251,328}: \quad \text { then: } \mathrm{K}=4620
$$


P - Pressure (mmHg), T - Tension (Kgf), L - The circumference $(\mathrm{cm}), \mathrm{B}$ - Width $(\mathrm{cm})$,

$\mathrm{N}$ - Number of layers applied.

When applying of a bandage, several forces arise may be mentioned: the longitudinal tension, the transverse tension, the pressure applied by the textile, the reaction force of the leg surface, the friction between textiles and leg area, shear forces, longitudinal and transverse textile flexion forces. When it comes to more layers, the upper layers still exert pressure on the lower layers. The total tension developed by an elastic band is equal to the sum of warp tensions yarns. The result is that the number of layers $(\mathrm{N})$, applied with a constant tension is proportional to the number of warp yarns in a point of application on the leg surface. Therefore it is essential to consider the number of layers in the calculations.

The level of compression generated by a bandage system is determined by complex interactions between the following main factors: the physical structure of the textile, the elastic properties, the size and form of the member, the qualification of nurses. In the model above, the pressure created by a bandage after installation depends on: the tension in the fabric, the number of layers applied, the radius of the member,

\section{MODELISATION}

\subsection{Model applied for one layer}

The pressure generated by a rigid or elastic material is inversely proportional to the circumference in the point of application; in this case it seems significant to consider the thickness of the fabric on the value of the applied pressure.

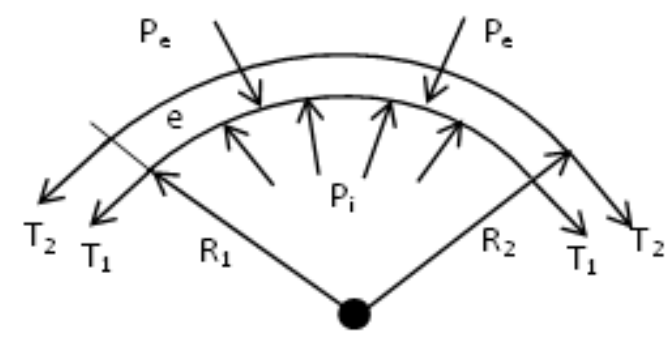

Fig.1. Model taking into account the thickness of the bandage

In this approach, the bandage is assumed cylindrical shape with a thickness (e) as shown in 
Figure 1. It is useful to introduce the following data to conclude on the influence of the thickness of the material.

$$
\begin{gathered}
\mathrm{T}_{\mathrm{M}}=\frac{\mathrm{T}_{1}+\mathrm{T}_{2}}{2} \\
\mathrm{D}_{1}=2 \mathrm{R}_{1} \\
\mathrm{D}_{2}=2 \mathrm{R}_{2}
\end{gathered}
$$

$\mathrm{T}_{\mathrm{M}}$ : Medium tension applied $(\mathrm{N}), \mathrm{D}_{1}$ : Inside application diameter $(\mathrm{m}), \mathrm{D}_{2}$ : Outside application diameter (m).

The wall of the cylinder is subject to three types of stresses, circumferential, longitudinal and transverse. If the ratio between the fabric thickness and the radius at the point of application is less than 0.1 , then the longitudinal stresses are negligible. In this case, thickness of the elastic band is not considered. In the opposite case it is necessary to take into account the thickness as in the case of multilayer bandages. Usually the number of layers cannot exceed 4 . The hoop stress (tangential) may be described as a function of the applied tension (T), the length (L) of an element and the thickness (e). Based on the above assumptions, the hoop stress can be presented by the following equation:

$$
\sigma_{\mathrm{H}}=\frac{\mathrm{P} \cdot \mathrm{D}}{2 \mathrm{e}}
$$

$\sigma_{\mathrm{H}}$ : Tangentiel stress $\left(\mathrm{N} / \mathrm{m}^{2}\right), \mathrm{P}:$ Internal pressure $\left(\mathrm{N} / \mathrm{m}^{2}\right), \mathrm{D}:$ Application diameter $(\mathrm{m})$

e : Material thickness (m), B : Bandage Width (m)

$$
\sigma_{\mathrm{H}}=\frac{\mathrm{F}}{\mathrm{S}}=\frac{\mathrm{T}}{\mathrm{e} \cdot \mathrm{B}}
$$

S: The application surface

And:

$$
\mathrm{P}=\mathrm{C} \cdot \frac{2 \mathrm{~T}}{\mathrm{D} \cdot \mathrm{B}}, \mathrm{C}=0.0075
$$

This equation does not take into account the thickness of the fabric, thus the thickness of the bandage does not influence the pressure interface produced by the applied textile. This model is used to calculate the pressure in the case of use of layer.

\subsection{Model applied for multiple layers}

Considering two elastic textiles made from textile materials with elastic moduli $E_{1}$ and $E_{2}$ $\left(\mathrm{N} / \mathrm{m}_{2}\right)$, the radius applied in centers of the two materials are respectively $\mathrm{R}_{1}$ and $\mathrm{R}_{2}$ and 
having thicknesses $\mathrm{e}_{1}$ and $\mathrm{e}_{2}$, as illustrated in Figure 2.

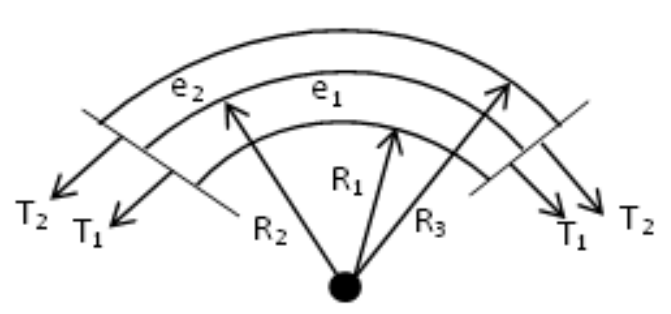

Fig.2. Model taking into account the thickness and number of layers

The total tension (T) applied distributed between the two fabrics is presented by the equation (19).

$$
\mathrm{T}=\sigma_{1} \cdot 2 \pi \cdot \mathrm{R}_{1}^{\prime} \cdot \mathrm{e}_{1}+\sigma_{2} \cdot 2 \pi \cdot \mathrm{R}_{2}^{\prime} \cdot \mathrm{e}_{2}
$$

$\mathrm{R}_{1}^{\prime}=\mathrm{R}_{2}-\mathrm{R}_{1}$

$\mathrm{R}_{2}^{\prime}=\mathrm{R}_{3}-\mathrm{R}_{2}$

$\sigma_{1}$ maximum stress of textiles 1

$\sigma_{2}$ maximum stresse of textile 2

By compatibility, the two textiles develop the same axial stress $(\varepsilon)$ :

$$
\varepsilon=\frac{\sigma_{1}}{\mathrm{E}_{1}}=\frac{\sigma_{2}}{\mathrm{E}_{2}}
$$

Combining expressions (19) and (20), the following equation defines the total tension applied by the two textiles:

$$
\mathrm{T}=\frac{\left(\varepsilon \mathrm{E}_{1} \cdot 2 \pi \cdot \mathrm{R}_{1} \cdot \mathrm{e}_{1}+\varepsilon \cdot \mathrm{E}_{2} \cdot 2 \pi \cdot \mathrm{R}_{2} \cdot \mathrm{e}_{2}\right)}{\mathrm{C}}=\frac{\varepsilon 2 \pi\left(\mathrm{E}_{1} \mathrm{R}_{1} \mathrm{e}_{1}+\mathrm{E}_{2} \mathrm{R}_{2} \mathrm{e}_{2}\right)}{\mathrm{C}}
$$

Because of the thicknesses $e_{1}$ et $e_{2}$ are very small $\left(\frac{e_{1}}{R_{1}}<\frac{1}{10}\right.$, et $\left.\frac{e_{2}}{R_{2}}<\frac{1}{10}\right)$, the radius $R_{1}$ et $\mathrm{R}_{2}$ are the same then: $\left(\mathrm{R}=\mathrm{R}_{1}=\mathrm{R}_{2}\right)$, and using the Laplace low:

$$
\mathrm{P}=\frac{\mathrm{T}}{\mathrm{R}}=\left(\frac{1}{\mathrm{R}}\right) \frac{\varepsilon \cdot 2 \pi \cdot \mathrm{R}\left(\mathrm{E}_{1} \cdot \mathrm{e}_{1}+\mathrm{E}_{2} \cdot \mathrm{e}_{2}\right)}{\mathrm{C}} \frac{\varepsilon \cdot 2 \pi\left(\mathrm{E}_{1} \cdot \mathrm{e}_{1}+\mathrm{E}_{2} \cdot \mathrm{e}_{2}\right)}{\mathrm{C}}
$$

If three layers are used with the same or different bandages, and applying with the same principle of very small thickness, the three layers will have a total pressure on the leg of:

$$
\mathrm{P}=\frac{\varepsilon \cdot 2 \pi\left(\mathrm{E}_{1} \cdot \mathrm{e}_{1}+\mathrm{E}_{2} \cdot \mathrm{e}_{2}+\mathrm{E}_{3} \cdot \mathrm{e}_{3}\right)}{\mathrm{C}}
$$

$\mathrm{E}_{3}, \mathrm{e}_{3}$ are respectively the elastic modulus and the thickness of the third band. If this hypothesis is always true for the case where one uses several materials with different elastic modulus, then 
the pressure exerted by (n) layers is presented by the following expression:

$$
\mathrm{P}=\frac{\varepsilon 2 \pi \sum_{\mathrm{i}=1}^{\mathrm{n}}\left(\mathrm{E}_{\mathrm{i}} \cdot \mathrm{e}_{\mathrm{i}}\right)}{\mathrm{C}}
$$

\section{RESULTS AND DISCUSSION}

The calculations are done for each section with three turns on the prototype in the four zones as shown in figure 3 :

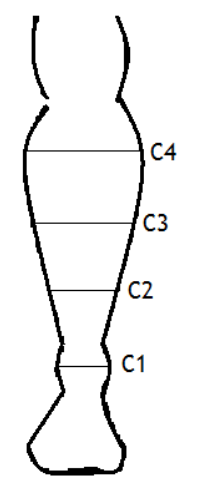

Fig.3. Shape of leg with the considered zones

$\mathrm{C}_{1}=260 \mathrm{~mm}-$ Section of the ankle

$\mathrm{C}_{2}=280 \mathrm{~mm}$ - section above the ankle

$\mathrm{C}_{3}=330 \mathrm{~mm}-$ Section below the calf

$\mathrm{C}_{4}=390 \mathrm{~mm}$ - calf section

The final properties of textiles depend more or less on many different technical and technological parameters, which should already be adjusted during the design phase of a textile. To predict interfacial pressure induced by different textile structure on a curved surface of the human body, the relationship between the tensile properties of an elastic fabric, the curvature of the shaped surface, and the pressure of the skin and textile interfacial may be formulated into a mathematical expression.

The different degrees of elasticity and materials strength with different degrees of weave tension can induce different degrees of pressure on patients. A lot of elastic textile fabrics are produced using weaving needle looms techniques.

Therefore, a variety of samples were adopted until an optimum bandage will produce. For all calculations and practical experiences we used the three samples taken during work earlier as shown in Table 1. 
Table 1. Characteristics of the study samples

\begin{tabular}{|c|c|c|c|c|c|}
\hline \multirow[t]{2}{*}{ Characteristics } & \multirow[t]{2}{*}{ Designations } & \multirow[t]{2}{*}{ Units } & \multicolumn{3}{|c|}{ Samples } \\
\hline & & & $\mathrm{E}_{6}$ & $\mathrm{E}_{5}$ & $\mathrm{E}_{\mathrm{f}}$ \\
\hline Twist rate of warp yarns direction & $\mathrm{k}$ & $\mathrm{Tr} / \mathrm{m}$ & 900 & 900 & 900 \\
\hline Weft density & $\mathrm{P}_{\mathrm{tr}}$ & Yarns $/ 10 \mathrm{~cm}$ & 180 & 90 & 126 \\
\hline Weft average diameter & $\mathrm{d}_{\mathrm{tr}}$ & $\mathrm{mm}$ & 0.20 & 0.20 & 0.20 \\
\hline Elongation under fixed load (800 & $\mathrm{Al}$ & $\%$ & 108 & 86 & 92 \\
\hline Widh & B & $\mathrm{mm}$ & 100 & 100 & 100 \\
\hline Structure & - & - & Plain & Plain & Plain \\
\hline & & & weave & weave & weave \\
\hline
\end{tabular}

This includes the tension applied on to textiles and corresponding elongations during each phase in the ascending or descending direction. It should be noted that the elongations and the tensions applied onto the textile are important parameters for the calculation of the pressure in use. They also help to make conclusions in the practical application of bandages. In Table 2, 3, 4 and 5 are presented the tensions (T) values specific to each sample (E) and the corresponding elongations $\left(\mathrm{A}_{\mathrm{l}}\right)$ and the tensions are calculated experimentally.

Table 2. Pressures calculated on samples $\mathrm{E}_{5}, \mathrm{E}_{6}$ and $\mathrm{Ef}$ in the $\mathrm{C}_{1}$ zone

\begin{tabular}{|c|c|c|c|c|c|c|}
\hline $\mathrm{E}_{5}:$ Tension $\mathrm{T}_{5}$ & $\mathrm{E}_{5} \mathrm{C}_{1}:$ & & $\mathrm{E}_{6}:$ Tension & $\mathrm{E}_{6} \mathrm{C}_{1}:$ & $E_{f}:$ Tension & $\mathrm{E}_{\mathrm{f}} \mathrm{C}_{1}:$ \\
\hline$(\mathrm{cN}) \times 10$ & Pressure & $\mathrm{P}_{5}$ & T6 $(\mathrm{cN}) \times 10$ & Pressure & $\mathrm{T}_{\mathrm{f}}(\mathrm{cN}) \times 10$ & Pressure \\
\hline 14 & 7,46 & & 28 & 14,93 & 21 & 11,19 \\
\hline 20 & 10,66 & & 39 & 20,79 & 30 & 15,99 \\
\hline 28 & 14,93 & & 54 & 28,79 & 41 & 21,86 \\
\hline 36 & 19,19 & & 67 & 35,72 & 50 & 26,65 \\
\hline 45 & 23,99 & & 79 & 42,11 & 58 & 30,92 \\
\hline 52 & 27,72 & & 87 & 46,38 & 65 & 34,65 \\
\hline 61 & 32,52 & & 96 & 51,18 & 71 & 37,85 \\
\hline 68 & 36,25 & & 101 & 53,84 & 78 & 41,58 \\
\hline 74 & 39,45 & & 104 & 55,44 & 82 & 43,71 \\
\hline 80 & 42,65 & & 107 & 57,04 & 88 & 46,91 \\
\hline 86 & 45,84 & & 108 & 57,57 & 92 & 49,04 \\
\hline
\end{tabular}


Table 3. Pressures calculated on samples $E_{5}, E_{6}$ and $E f$ in the $C_{2}$ zone

\begin{tabular}{|c|c|c|c|c|c|}
\hline $\begin{array}{c}\mathrm{E}_{5}: \text { Tension } \\
\mathrm{cNx} 10\end{array}$ & $\begin{array}{l}E_{5} C_{2}: \\
\text { Pressure }\end{array}$ & $\begin{array}{l}\mathrm{E}_{6}: \text { Tension } \\
\mathrm{cNx} 10\end{array}$ & $\begin{array}{l}E_{6} C_{1}: \\
\text { Pressure }\end{array}$ & $\begin{array}{l}\mathrm{E}_{\mathrm{f}}: \text { Tension } \\
\mathrm{cNx} 10\end{array}$ & $\begin{array}{l}\mathrm{E}_{\mathrm{f}} \mathrm{C}_{2}: \\
\text { Pressure }\end{array}$ \\
\hline 14 & 6,93 & 28 & 13,86 & 21 & 10,4 \\
\hline 20 & 9,9 & 39 & 19,31 & 30 & 14,85 \\
\hline 28 & 13,86 & 54 & 26,73 & 41 & 20,3 \\
\hline 36 & 17,82 & 67 & 33,17 & 50 & 24,75 \\
\hline 45 & 22,26 & 79 & 39,11 & 58 & 28,71 \\
\hline 52 & 25,74 & 87 & 43,07 & 65 & 32,18 \\
\hline 61 & 30,2 & 96 & 47,52 & 71 & 35,15 \\
\hline 68 & 33,66 & 101 & 49,99 & 78 & 38,61 \\
\hline 74 & 36,63 & 104 & 51,48 & 82 & 40,59 \\
\hline 80 & 39,6 & 107 & 52,97 & 88 & 43,56 \\
\hline 86 & 42,57 & 108 & 53,46 & 92 & 45,54 \\
\hline
\end{tabular}

Table 4. Pressures calculated on samples $\mathrm{E}_{5}, \mathrm{E}_{6}$ and $\mathrm{Ef}$ in the $\mathrm{C}_{3}$ zone

\begin{tabular}{llllll}
\hline $\mathrm{E}_{5}:$ Tension & $\mathrm{E}_{5} \mathrm{C}_{3}:$ & $\mathrm{E}_{6}:$ Tension & $\mathrm{E}_{6} \mathrm{C}_{3}:$ & $\mathrm{E}_{\mathrm{f}}:$ Tension & $\mathrm{E}_{\mathrm{f}} \mathrm{C}_{3}:$ \\
$\mathrm{cNx} 10$ & Pressure & $\mathrm{cNx} 10$ & Pressure & $\mathrm{cNx} 10$ & Pressure \\
\hline 14 & 5,88 & 28 & 11,76 & 21 & 8,82 \\
20 & 8,4 & 39 & 16,38 & 30 & 12,6 \\
28 & 11,76 & 54 & 22,68 & 41 & 17,22 \\
36 & 15,12 & 67 & 28,14 & 50 & 21 \\
45 & 18,9 & 79 & 33,18 & 58 & 24,36 \\
52 & 21,84 & 87 & 36,54 & 65 & 27,3 \\
61 & 25,62 & 96 & 40,32 & 71 & 29,82 \\
68 & 28,56 & 101 & 42,42 & 78 & 32,76 \\
74 & 31,08 & 104 & 43,68 & 82 & 34,44 \\
80 & 336 & 107 & 4494 & 88 & 3696 \\
86 & 36,12 & 108 & 45,36 & 92 & 38,64 \\
\hline
\end{tabular}


Table 5. Pressures calculated on samples $\mathrm{E}_{5}, \mathrm{E}_{6}$ and $\mathrm{Ef}$ in the $\mathrm{C}_{1}$ zone

\begin{tabular}{llllll}
\hline $\mathrm{E}_{5}:$ Tension & $\mathrm{E}_{5} \mathrm{C}_{4}:$ & $\mathrm{E}_{6}:$ Tension & $\mathrm{E}_{6} \mathrm{C}_{4}:$ & $\mathrm{E}_{\mathrm{f}}:$ Tension & $\mathrm{E}_{\mathrm{f}} \mathrm{C}_{4}:$ \\
$\mathrm{cNx} 10$ & Pressure & $\mathrm{cNx} 10$ & Pressure $\mathrm{mm}$ & $\mathrm{cNx} 10$ & Pressure mm \\
\hline 14 & 4,98 & 28 & 9,95 & 21 & 7,46 \\
20 & 7,11 & 39 & 13,56 & 30 & 10,66 \\
28 & 9,95 & 54 & 19,19 & 41 & 14,57 \\
36 & 12,79 & 67 & 23,81 & 50 & 17,77 \\
45 & 15,99 & 79 & 28,08 & 58 & 20,61 \\
52 & 18,48 & 87 & 30,91 & 65 & 23,1 \\
61 & 21,68 & 96 & 34,12 & 71 & 25,23 \\
68 & 24,17 & 101 & 35,89 & 78 & 27,72 \\
74 & 26,3 & 104 & 36,96 & 82 & 29,14 \\
80 & 28,43 & 107 & 38,03 & 88 & 31,27 \\
86 & 30,56 & 108 & 38,38 & 92 & 32,7 \\
\hline
\end{tabular}

From graphs in figures 3, 4, 5, 6, 7 and 8, it is clear that the tension is the first factor that directly influences with a large percentage on the pressure of the textile surface. These graphic data are very important because they can clearly see the applied tensions and choose them for a good practical application of hospital bandages. In the graphs which follow, $\mathrm{C}$ is the circumference in $(\mathrm{mm})$ and $\mathrm{P}$ is the pressure in $(\mathrm{mm} \mathrm{Hg})$.

\subsection{Textile single layer}

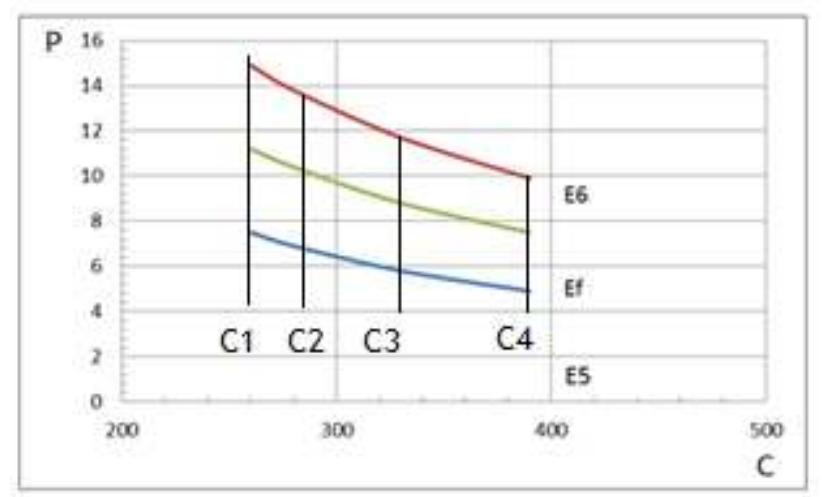

Fig.4. Relation between the pressure and the circumference of the leg (minimum pressure) 


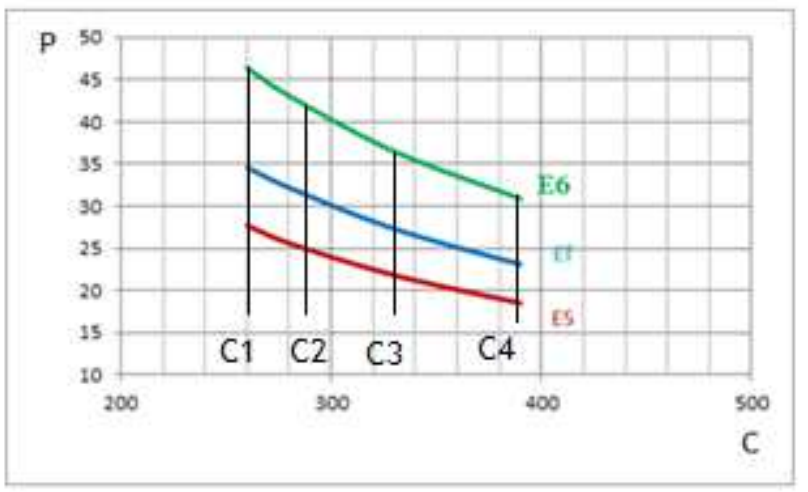

Fig.5. Relation between the pressure and the circumference of the leg (medium pressure)

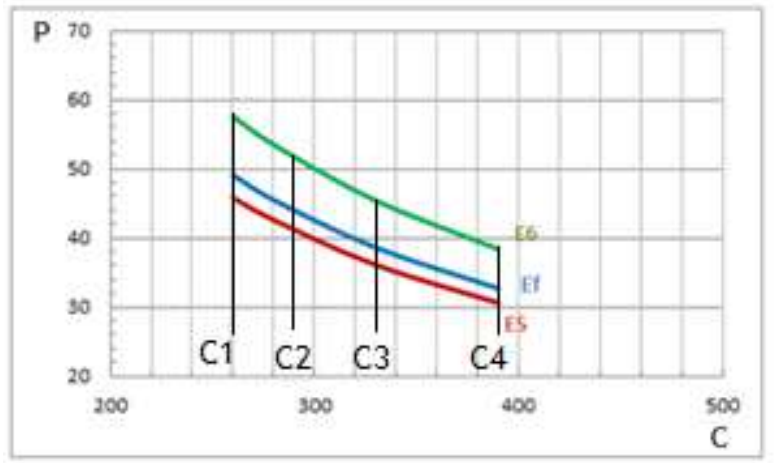

Fig.6. Relationship between the pressure and leg circumference (maximum pressures)

For the applied minimum pressures, the pressure difference at the ankle bandage between the $\mathrm{E}_{5}$ and $\mathrm{E}_{6}$ is $7.4 \mathrm{~mm} \mathrm{Hg}$. The same pressure difference at the calf level is $5 \mathrm{mmHg}$. For the applied maximum pressures, the pressure difference at the ankle between $E_{5}$ and $E_{6}$ is 11.8 $\mathrm{mm} \mathrm{Hg}$. The same pressure difference at calf level is $7.8 \mathrm{~mm} \mathrm{Hg}$.

\subsection{Multiple layer textile}

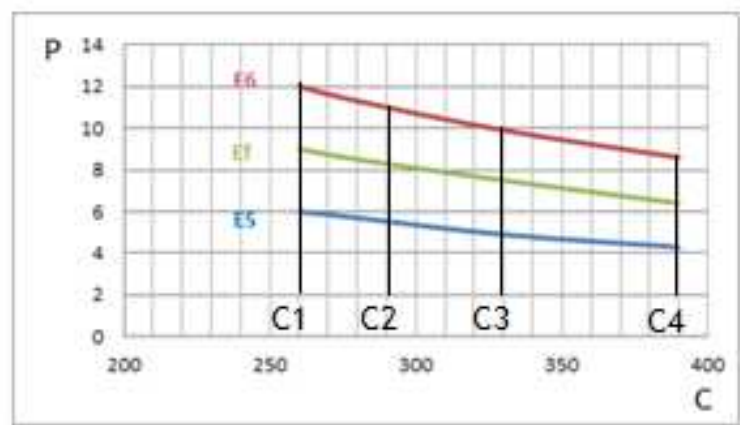

Fig.7. Relation between the pressure and the circumference of the leg (minimum pressure) 


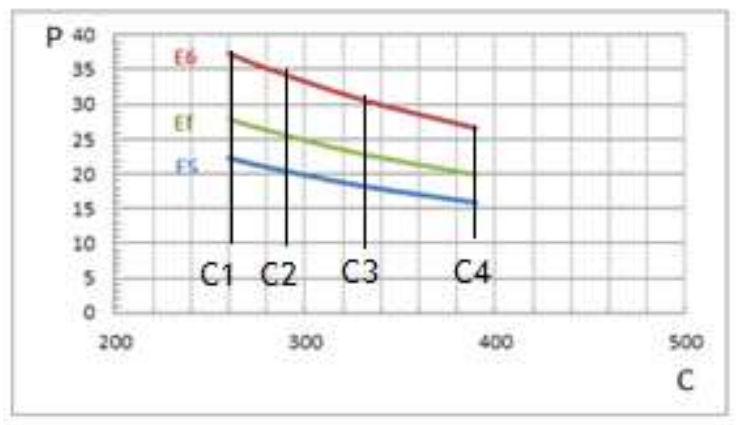

Fig.8. Relation between the pressure and the circumference of the leg (medium pressure)

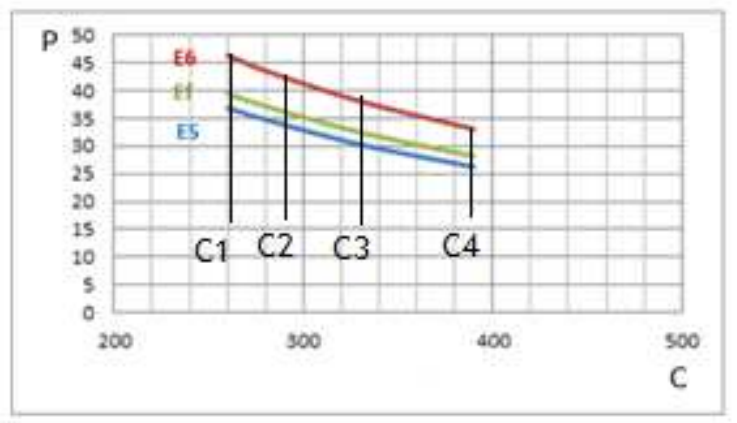

Fig.9. Relationship between the pressure and leg circumference (maximum pressures)

We note that the pressure difference at the ankle is much greater than the pressure difference at the calf, this also confirms when employing low pressure and high pressure. If we consider the final sample $E_{\mathrm{f}}$, and the same assumptions, the pressure difference is $3.7 \mathrm{~mm} \mathrm{Hg}$ compared with $\mathrm{E}_{5}$ bandage at the ankle in the case of minimum pressure values while the pressure difference at the calf with the value of the sample $\mathrm{E}_{5}$, is $2.6 \mathrm{~mm} \mathrm{Hg}$. In the case of the maximum values of applied pressure, at the ankle, the pressure difference between $\mathrm{E}_{\mathrm{f}}$ and $\mathrm{E}_{5}$ bandage is $3.3 \mathrm{~mm} \mathrm{Hg}$, and $2.1 \mathrm{~mm} \mathrm{Hg}$ at the calf for the same bandage.

\section{CONCLUSION}

The $\mathrm{E}_{\mathrm{f}}$ bandage exerts moderate pressures compared to other models because the pressure difference with the other tires is low; the difference between the ankle and calf in the case of Ef bandage for minimum values is $1.1 \mathrm{~mm} \mathrm{Hg}$ while the same difference for the $\mathrm{E}_{6}$ band is $2.4 \mathrm{~mm} \mathrm{Hg}$. The difference in pressure between the ankle and calf in the case of pressure to the Ef bandage is $1.2 \mathrm{~mm} \mathrm{Hg}$ while the same difference for the $\mathrm{E}_{5}$ sample is $4 \mathrm{~mm} \mathrm{Hg}$. 
The results show that simple bandages multilayer develop much higher pressure than those said multilayer, the multilayer bandages exert much more uniform pressure than single layered bandages. Considering the same bandage with an application of multiple layers, we can say that the bandage $\mathrm{E}_{\mathrm{f}}$ presents the optimal characteristics and has moderate pressures compared to other models because the pressure difference with the other bandage is low. The pressures are more uniform and the results are satisfactory as they are within the limits of the standards indicated previously.

\section{ACKNOWLEDGEMENTS}

I want to introduce my sincere thanks for the TEXALG group on the technical visits to its textile complexs.

\section{REFERENCES}

[1] Marieb E.N, Hoehn K. Human Anatomy and Physiology. Pearson Benjamin Cummings, 2007, 7 th edition.

[2] Ruckley C. V, Evans C. J, Allan P. L, Lee A. J, Fowkes F. G. Chronic venous insufficiency, Clinical and duplex correlations. The Edinburgh Vein Study of venous disorders in the general population. Journal of Vascular Surgery, 2002, 36(3), 520-525.

[3] Mozes G, Gloviczki P. Venous embryology and anatomy. In J.J. Bergan, editor, The Vein Book, 2007 Elsevier Academic Press, San Diego, CA, pages 15-25.

[4] Beebe-Dimmer J. L, Pfeifer J. R, Engle J. S, Schottenfeld D. The épidemiology of chronic venous insufficiency and varicose veins. Annals of Epidemiology, 2005, 15 (3), 175-184.

[5] Downie S.P, Raynor S.M, Firmin D.N, Wood N.B, Thom S.A, Hughes A.D, Parker K.H, Wolfe J.H.N, Xu X.Y. Effects of elastic compression stockings on Walls hear stress in deep and superficial veins of the calf. Am. J. Physiol Heart Circ. Physiol. 2008, 294(5), H 2112-2120.

[6] Gardner A.M.N, Fox R.H. The return of blood to the heart: venous pumps in health and disease. 1993, John Libbey \& company Ltd, 2nd edition.

[7] Partsch H. The static stiness index: A simple method to assess the elastic property of compression material in vivo. Dermatologic Surgery, 2005, 31(6):625-630. 
[8] Onofrei E, Rocha A, Catarino M. A. Thermal comfort properties of knitted fabrics made of elastane and bioactive yarns. In: Proceedings of the Fiber Society Spring. International Conference on Fibrous Materials, Bursa, Turkey, 2010, pp. 145-146.

[9] O'Meara S, Cullum N.A, Nelson E.A. Compression for venous leg ulcers. Cochrane Database of Systematic Reviews, 2009 (1).

[10] Nelson E.A, Harper D.R, Prescott R.J, Gibson B, Brown D, Ruckley C.V. Prevention of recurrence of venous ulceration: randomized controlled trial of class 2and class 3 elastic compression. Journal of Vascular Surgery, 2006 44(4):803-808.

[11] Milic D.J, Zivic S.S, Bogdanovic D.C, Jovanovic M.M, Jankovic R.J, Milosevic Z.D, Stamenkovic D.M, Trenkic M.S. The influence of different sub-bandage pressure values on venous leg ulcers healing when treated with compression therapy. Journal of Vascular Surgery, 2010, 51(3).

[12] Coull A, Tolson D, Mcintosh J. Class-3c compression bandaging for venous ulcers: comparison of spiral and figure-of-eight techniques. Journal of Advanced Nursing 2006, 54(3):274-283.

\section{How to cite this article:}

Halfaoui R and Chemani B. New approach to predict pressure produced by an elastic textile in the therapeutic treatment of venous leg. J. Fundam. Appl. Sci., 2016, 8(2), 297-312. 